\title{
A single-center, multidisciplinary experience with radium-223 dichloride in men with metastatic castrate-resistant prostate cancer
}

Cédric Charrois-Durand ${ }^{1}$; Fred Saad ${ }^{2}$; Maroie Barkati ${ }^{1}$; Jean-Baptiste Lattouf ${ }^{2}$; Paul Perrotte ${ }^{2}$; Pierre I. Karakiewicz²; Denis Soulières ${ }^{3}$; Normand Blais ${ }^{3}$; Zineb Hamilou ${ }^{3}$; Daniel Juneau ${ }^{4}$; Nicolas Plouznikoff ${ }^{4}$; Daniel Taussky ${ }^{1}$; Guila Delouya ${ }^{1}$

${ }^{1}$ Department of Radiation Oncology, Centre hospitalier de l'Université de Montréal (CHUM), Montreal, QC, Canada; ${ }^{2}$ Department of Surgery, Division of Urology, CHUM, Montreal, QC, Canada; ${ }^{3}$ Department of Hemato-Oncology, CHUM, Montreal, QC, Canada; ${ }^{4}$ Department of Nuclear Medicine, CHUM, Montreal, QC, Canada

Cite as: Charrois-Durand C, Saad F, Barkati M, et al. A single-center, multidisciplinary experience with radium-223 dichloride in men with metastatic castrate-resistant prostate cancer. Can Urol Assoc J 2022 January 27; Epub ahead of print. http://dx.doi.org/10.5489/cuaj.7591

Published online January 27, 2022

Corresponding author: Dr. Guila Delouya, affiliations; guila.delouya.med@ssss.gouv.qc.ca

$* * *$

Abstract

Introduction: We aimed to investigate several clinical and biochemical parameters, including palliative external beam radiation therapy (EBRT) to predict survival in patients with metastatic castrate-resistant prostate cancer (mCRPC) treated with radium-223 $\left({ }^{223} \mathrm{Ra}\right)$.

Methods: We tested known and possible prognostic parameters, including palliative EBRT, both prior and concurrent to ${ }^{223} \mathrm{Ra}$. Log-rank test (Kaplan-Meier method) and Cox regression analysis were used to predict overall survival (OS).

Results: A total of 133 patients were treated with ${ }^{223} \mathrm{Ra}$; median age was 72 years. Median OS was 9.0 (95\% confidence interval [CI $7.4-10.6)$ months. By univariate analysis (log-rank test), baseline Eastern Cooperative Oncology Group performance status (ECOG PS) 0-1 ( $\mathrm{p}=0.001)$, $\geq 5$ cycles of ${ }^{223} \mathrm{Ra}(\mathrm{p}<0.001)$, baseline hemoglobin $(\mathrm{Hb}) \geq 120 \mathrm{~g} / \mathrm{L}(\mathrm{p}<0.001)$, baseline total alkaline phosphatase (tALP) $<110 \mathrm{U} / \mathrm{L}(\mathrm{p}=0.001)$, and any prostate-specific antigen (PSA) decline at week $12(\mathrm{p}=0.013)$ were associated with increased OS. EBRT prior and/or concurrent to ${ }^{223} \mathrm{Ra}$ showed a trend $(\mathrm{p}=0.051)$ towards inferior OS by univariate analysis only. By multivariate analysis, significant factors were PS 0-1 (hazard ratio [HR] 1.94, 95\% CI 1.3-2.9, $\mathrm{p}=0.001), \mathrm{Hb} \geq 120 \mathrm{~g} / \mathrm{L}$ (HR 0.5, 95\% CI 95\% CI 0.3-0.9, p =0.011), and absence of docetaxel use prior to ${ }^{223} \mathrm{Ra}$ (HR 1.86, 95\% CI 1.08-3.22, $\mathrm{p}=0.026$ ). With baseline Hb, tALP, and ECOG PS, we were able to divide patients into three groups with different median OS (months): 23.0 
(95\% CI 12.8-33.2), 8.0 (95\% CI 6.7-9.3), and 5.0 (95\% CI 3.1-6.9) for low-, intermediate-, and high-risk, respectively $(\mathrm{p}<0.001)$.

Conclusions: We found that ${ }^{223} \mathrm{Ra}$ therapy can result in an OS of close to two years in carefully selected patients. Earlier administration of ${ }^{223}$ Ra therapy to fitter patients with mCRPC should be tested.

\section{Introduction}

The treatment sequence of different available agents for metastatic castrate-resistant prostate cancer (mCRPC) poses a challenge due to poor overall survival (OS) ${ }^{1}$. Several novel therapies have emerged that demonstrate a survival benefit in this setting ${ }^{2-7}$. The bone selective, calcium mimetic radium-223 dichloride (Ra-223) is a short-range, alpha particle emitter that showed a 3.6-month OS benefit over placebo in the ALSYMPCA trial ${ }^{7}$, with limited toxicity up to 3 years after treatment ${ }^{8}$. Various studies that followed aimed to determine whether specific parameters could help predict response to ${ }^{223} \mathrm{Ra}$ and survival ${ }^{9-13}$, such as the baseline Eastern Cooperative Oncology Group (ECOG) performance status (PS), prostate-specific antigen (PSA), and hemoglobin $(\mathrm{Hb})$, which have been validated ${ }^{14}$. Additionally, the ALSYMPCA trial demonstrated that ${ }^{223} \mathrm{Ra}$ therapy reduced pain and delayed the time to first palliative external beam radiation treatment (EBRT) ${ }^{7,15}$. In clinical practice, many patients will receive both ${ }^{223} \mathrm{Ra}$ treatment and EBRT, either sequentially or concurrently. The combination of EBRT and samarium-153 (Sm-153), a beta-emitting radiopharmaceutical used for pain alleviation in osseous metastatic patients, improved pain relief over Sm-153 therapy alone ${ }^{16}$. However, it remains unclear if EBRT and ${ }^{223} \mathrm{Ra}$ share a synergistic effect. As the first hospital center in our province to offer ${ }^{223} \mathrm{Ra}$ therapy to patients with $\mathrm{mCRPC}$, we possess one of the largest experiences with this treatment in Canada. In this study, we clarified whether certain clinical and biochemical parameters could effectively predict survival in mCRPC patients treated with ${ }^{223} \mathrm{Ra}$, and we investigated whether prior and/or concurrent palliative EBRT could impact prognosis in this population.

\section{Methods}

\section{Data source}

Patients were assessed and identified by reviewing our institutional electronic database and all medical records of patients who received ${ }^{223} \mathrm{Ra}$ treatment. The institutional ethics committee's (Number 19.369) approbation was obtained for this study. No signed informed consent was necessary. 


\section{Outcomes of interest}

We report on OS as well as predictive factors for better survival. OS was defined as the time from the first ${ }^{223} \mathrm{Ra}$ treatment to the time of death, regardless of cause. Known prognostic factors such as baseline ECOG PS, PSA levels, Hb levels, total alkaline phosphatase (tALP) levels, lactate dehydrogenase (LDH) levels, and neutrophil-to-lymphocyte ratio (NLR) were tested. We also reviewed previous systemic therapies as well as palliative radiation treatment before and/or during ${ }^{223} \mathrm{Ra}$ treatment as possible prognostic parameters. We used baseline parameters associated with OS to create a score to help predict survival in men with mCRPC treated with ${ }^{223} \mathrm{Ra}$.

\section{Study population and intervention}

Complete medical history, including prior systemic therapies for $\mathrm{mCRPC}$ and ECOG PS recorded at the first consultation, was obtained from electronic records. Eligibility for ${ }^{223} \mathrm{Ra}$ therapy had to be confirmed in multidisciplinary tumor boards for all patients. Inclusion and exclusion criteria were the same as in the ALSYMPCA trial ${ }^{7}$. In contrast to other provinces where no government agency determines in what order patients can be treated with ${ }^{223} \mathrm{Ra}$, in our province ${ }^{223} \mathrm{Ra}$ is approved only for patients who progressed during or after docetaxel therapy unless there was a contraindication or intolerance to this agent ${ }^{17}$. Prior to 2018 , patients received this treatment in the radiation oncology department; thereafter, treatment was administered in the nuclear medicine department. Patients received 50 to $55 \mathrm{kBq} / \mathrm{kg}$ of ${ }^{223} \mathrm{Ra}$, administered intravenously every 4 weeks for a total of 6 cycles. Before each cycle of ${ }^{223} \mathrm{Ra}$, levels of PSA, tALP, and LDH as well as complete blood counts including the NLR, were recorded. ALP and PSA decline were respectively defined as any decrease in tALP value and PSA value after 12 weeks (before cycle 4) compared to baseline. For patients that had their blood tests outside of our center, some results were not available for study purposes. Records of pain and opiate use were not standardized and were therefore not analyzed. Finally, we retrospectively noted if patients received prior and/or concurrent palliative radiation therapy relative to their ${ }^{223} \mathrm{Ra}$ treatments. All patients with mCRPC who received at least one cycle of ${ }^{223} \mathrm{Ra}$ since the introduction of this service at the CHUM in 2013 were included in our analysis.

\section{Statistical analysis}

Log-rank test (Kaplan-Meier method) was used for OS analysis. For univariate analysis of survival, either the median value or a value rounding up or down from the median value was used as the cut-off for the following factors: age, the number of ${ }^{223}$ Ra cycles received, previous systemic therapies used, baseline ECOG PS, Hb, PSA, tALP, LDH, and NLR, a decline in PSA and tALP, and the timing of palliative EBRT (before and/or during). Factors with a $p$-value $<0.1$ were included in a multivariate analysis using the Cox regression analysis. The distribution of categorical variables was analyzed using the Chi-square test or Fisher's exact test. Statistical analysis was done with SPSS 26.0 for Windows (IBM SPSS, Chicago, Illinois). 


\section{Results}

Between October 2013 and June 2021, a total of 133 patients were treated with ${ }^{223} \mathrm{Ra}$ at our institution. At the time of analysis, 6 patients had ongoing treatment. Characteristics of our patients are shown in Table 1. Median age was 72 years old. Median OS for the entire cohort was 9.0 months (95\% CI 7.4-10.6 months). Previous systemic therapies included docetaxel $(n=84)$, abiraterone $(n=75)$, cabazitaxel $(n=11)$, and enzalutamide $(n=50)$. Sixty-one patients $(46 \%)$ received palliative EBRT before ${ }^{223} \mathrm{Ra}$ and 20 patients $(15 \%)$ received it concurrently. Fortyeight patients discontinued treatment before the $6^{\text {th }}$ cycle. Reasons for non-completion of therapy are shown in Table 2.

Univariate analyses of factors associated with OS are shown in Table 3. Factors associated with longer OS were baseline ECOG PS 0, 1 vs. 2 (11.0 months, 95\% CI 7.9-14.1 vs. 6.0 months, $95 \%$ CI3.7-8.3, p=0.001), as well as baseline $\mathrm{Hb}$ value $\geq 120 \mathrm{vs.}<120 \mathrm{~g} / \mathrm{L}(13.0$ months, 95\% CI 10.4-15.6 vs. 8.0 months, 95\% CI 6.9-9.1, $\mathrm{p}<0.001)$ and baseline tALP value $<110$ vs. $>110$ U/L (12.0 months, 95\% CI8.9-15.1 vs. 8.0 months, 95\% CI 7.4-8.6, $\mathrm{p}=0.001)$. Baseline PSA $(p=0.15)$, NLR $(p=0.90)$, and LDH $(p=0.065)$ did not predict OS. Any PSA decline at week 12 (before cycle 4 ) vs. no decline was associated with increased OS (17.0 months, 95\% CI 12.4-21.6 vs. 10.0 months, 95\% CI 7.2-12.8, $\mathrm{p}=0.013)$, but tALP decline was $\operatorname{not}(\mathrm{p}=0.60)$. Patients who received palliative EBRT before and/or during ${ }^{223} \mathrm{Ra}$ treatment had a trend towards worse OS compared to patients who did not receive any EBRT $(\mathrm{p}=0.051)$. Patients who received $\geq 5$ cycles of ${ }^{223}$ Ra vs. $1-4$ cycles had a longer OS (15.0 months, 95\% CI 12.2-17.8 vs. 3.0 months, $95 \%$ CI 1.8-4.3, $\mathrm{p}<0.001)$. To test if the longer survival in patients who received $\geq 5$ cycles of ${ }^{223} \mathrm{Ra}$ was due to the fact that patients who died before they were able to complete all six cycles, we eliminated all patients who lived for less than 6 months. Eighty-nine patients were analyzed for this landmark analysis. The previous findings were confirmed: patients who received $\geq 5$ cycles $(\mathrm{N}=81)$ had a median OS of 15.0 months (95\% CI 12.6-17.4 months) compared to 8.0 months (95\% CI not calculated) for patients who received 1-4 cycles $(\mathrm{N}=9)$, $\mathrm{p}=0.022$.

Multivariate analysis is shown in Table IV. Significantly poor OS predictors were high ECOG PS (hazard ratio (HR) 1.94, 95\% CI 1.3-2.9, $p=0.001$ ) and prior docetaxel use (HR 1.86, $95 \%$ CI 1.1-3.2, $p=0.026$ ). High baseline $\mathrm{Hb}$ was associated with better survival (HR $0.5,95 \%$ CI $0.3-0.9, p=0.011)$.

In a binary regression analysis predicting for receiving 5-6 cycles, only increasing age as a continuous variable was associated with $5-6$ cycles (OR 1.04, 95\% CI 1.0-1.09, $\mathrm{p}=0.045)$ but not a $\mathrm{Hb}$ at baseline $\geq 120(\mathrm{p}=0.2)$, baseline tALP value $>110 \mathrm{U} / \mathrm{L}(\mathrm{p}=0.3)$ or ECOG $0-1$ $(\mathrm{p}=0.09)$.

Patients who were treated with docetaxel before ${ }^{223} \mathrm{Ra}$ were not more likely to have a baseline $\mathrm{Hb}<120 \mathrm{~g} / \mathrm{L}(45 \%)$ vs. patients who did not receive prior docetaxel $(48 \%)(p=$ n.s.). 
Patients who received a second line of chemotherapy with cabazitaxel were more likely to have a lower baseline $\mathrm{Hb}$, but this did not reach statistical significance ( $65 \%$ vs. $43 \%, p=0.08$ ).

We then tested whether a combination of three baseline values (ECOG PS, tALP, and Hb) could predict patients' survival before the start of ${ }^{223} \mathrm{Ra}$. We gave more weight to the PS because of its overall importance visible in the Kaplan-Meier analysis. Patients who had a PS of 0 or 1 and a $\mathrm{Hb}$ of $\geq 120 \mathrm{~g} / \mathrm{L}$ as well as a tALP $\geq 110 \mathrm{U} / \mathrm{L}$ were classified as low risk. We were able to divide patients into three groups with a median OS of 23.0 (95\% CI 12.8-33.2), 8.0 (95\% CI 6.7-9.3), and 5.0 (95\% CI 3.1-6.9) for low, intermediate, and high risk, respectively ( $\mathrm{p}<0.001)$ Table 5 and Figure 1.

\section{Discussion}

In our analysis of 133 patients treated with ${ }^{223} \mathrm{Ra}$, we found that a better ECOG PS, 5-6 cycles of ${ }^{223} \mathrm{Ra}$, baseline $\mathrm{tALP} \leq 110 \mathrm{U} / \mathrm{L}$, baseline $\mathrm{Hb} \geq 120 \mathrm{~g} / \mathrm{L}$, and any PSA decline at week 12 were associated with a prolonged median OS. By multivariate analysis, factors predicting better OS included low baseline ECOG PS, high baseline $\mathrm{Hb}$ and absence of prior docetaxel use. Patients who received palliative EBRT to bone metastasis during ${ }^{223} \mathrm{Ra}$ had a similar survival to patients who were not treated with EBRT. EBRT before ${ }^{223}$ Ra showed a trend towards worse OS by univariate analysis only.

Our results are comparable to the ALSYMPCA trial ${ }^{7,15}$, despite the much lower OS rate, which was 14.9 months vs. 9.0 months in our patients. In the randomized trial, $58 \%$ received all 6 cycles (63\% in the radium group) compared to $56 \%$ of patients in our center. In an exploratory analysis of the ALSYMPCA trial ${ }^{10}$, baseline parameters such as poor ECOG PS, high values of tALP, LDH, and PSA were linked with a higher risk of death. We corroborated these findings, apart from baseline PSA, which was a non-significant predictor of OS in our experience. A possible explanation for this is that the ALSYMPCA trial reported a median baseline PSA for the

${ }^{223} \mathrm{Ra}$ group at $146 \mathrm{ng} / \mathrm{mL}$ compared to $65.30 \mathrm{ng} / \mathrm{mL}$ in our study. Furthermore, patients in the ALSYMPCA trial did not receive prior systemic therapies apart from docetaxel. The different combinations of multiple lines of treatments received by our patients may contribute to the apparent absence of an effect of baseline PSA level on survival. The exploratory analysis of ALSYMPCA also showed that at week 12, tALP, LDH and PSA respectively decreased from baseline in $87 \%, 51 \%$, and $27 \%$ of ${ }^{223}$ Ra patients. These declines were associated with an increased OS for tALP and LDH but not for PSA. However, these factors did not reach the surrogacy requirement. From our experience, we found that only $19 \%$ of patients had any decrease of PSA level before the fourth cycle and that such a decrease was associated with longer OS in univariate, but not multivariate analysis. In our patients, tALP response was not associated with OS. We did not analyze LDH decrease because of the scarcity of available LDH levels before cycle 4 . 
The number of cycles was associated with prolonged survival in other retrospective ${ }^{13,18}$ ${ }^{19}$ and non-randomized prospective ${ }^{20}$ trials as well. Our 6-month landmark analysis suggests this association is real and not the result of a survival bias.

In other retrospective studies of ${ }^{223} \mathrm{Ra}{ }^{11-14,18}$, ${ }^{21}$, clinical and baseline laboratory parameters and their changes during treatment showed varying associations with OS (Table VI). However, similar to our results, most authors found at least some association between OS and baseline Hb, tALP, and ECOG PS. We developed a risk score based on data before the start of ${ }^{223} \mathrm{Ra}$ with three easily available pre-treatment factors (baseline ECOG PS $0-1, \mathrm{Hb} \geq 120 \mathrm{~g} / \mathrm{L}$, and tALP $\leq 110 \mathrm{U} / \mathrm{L}$ ) that stratified patients into different, clinically meaningful risk groups (median OS 23.0, 8.0, and 5.0 months, respectively). Frantellizzi et al. produced ${ }^{9}$ and validated ${ }^{14} \mathrm{a}$ similar score using baseline ECOG PS ( 0 vs. 1 vs. $\geq 2$ ), baseline PSA ( $<20 \mathrm{vs.} \geq 20 \mathrm{ng} / \mathrm{mL}$ ), and baseline $\mathrm{Hb}(\geq 120$ vs. $<120 \mathrm{~g} / \mathrm{L}$ ). Median survival for their low, intermediate, and high-risk groups were 33 months (95\% CI 28.0-N/A months), 16 months (95\% CI 13.2-20.0 months), and 8 months (7.0-10.0 months), respectively, $p<0.0001$. Similarly, they concluded that their score was simple, reliable, and could help select patients who would benefit the most from ${ }^{223} \mathrm{Ra}$. Baczyk et al. ${ }^{16}$ found that a combination of Sm-153, an emitter of beta-particles, and EBRT on painful bone metastases provided a more complete pain response. We investigated if palliative EBRT to the bone had a synergetic effect with ${ }^{223} \mathrm{Ra}$ and resulted in better OS. Our results do not support this hypothesis since patients who received palliative EBRT during ${ }^{223} \mathrm{Ra}$ did not show better survival in multivariate analysis. However, when given prior to or concurrent with ${ }^{223} \mathrm{Ra}$, EBRT seemed to have a negative influence on OS in univariate analysis. Our findings that palliative EBRT did not negatively affect OS in multivariate analysis are reassuring since pain relief should not be denied prior treatment with radium.

We found that treatment with docetaxel before ${ }^{223} \mathrm{Ra}$ was associated with an increased risk of death (HR 1.86, 95\% CI 1.08-3.22, $p=0.026$ ) by multivariate analysis. The current recommendation by our provincial advisory board on health issues is to administer ${ }^{223} \mathrm{Ra}$ after docetaxel unless there is a medical contraindication or intolerance to this agent ${ }^{17}$. Our finding, supported by other retrospective reviews ${ }^{10-12}$, puts into question this recommendation. The hypothesis that patients who received docetaxel before ${ }^{223} \mathrm{Ra}$ had less benefit may be explained by the more advanced, aggressive and/or refractory disease ${ }^{11}$. With a unique mechanism of action and a favorable safety profile ${ }^{8},{ }^{223} \mathrm{Ra}$ offers multiple opportunities for combination and sequencing with other systemic therapies and is the subject of ongoing studies, but optimal timing of these combinations remains a challenge ${ }^{22} 23$.

The strength of this study is the relatively large cohort of patients for a single institution experience with ${ }^{223} \mathrm{Ra}$, whereas other reported experiences with more patients are all multiinstitutional. However, the retrospective nature of our study remains a major limitation regarding interpretation of results. Larger confirmatory studies are needed to validate our results. 


\section{Conclusion}

This retrospective review of a large Canadian single-center experience with ${ }^{223} \mathrm{Ra}$ confirms existing literature suggesting that patients who receive all 6 cycles of ${ }^{223} \mathrm{Ra}$ therapy leads to improved efficacy when administered earlier in the course of sequential systemic therapies. Careful selection of patients remains of the utmost importance and can be facilitated by our predictive risk score based on ECOG PS, Hb, and tALP before the start of ${ }^{223} \mathrm{Ra}$ to predict OS. Validation of our proposed predictive score for survival in a larger cohort of patients is warranted.

Conflict of interest: Bayer was originally involved in helping to build the database but had no access to the data or the writing of the article 


\section{References}

1. Wallace K, Landsteiner A, Bunner S, et al. Epidemiology and mortality of metastatic castration-resistant prostate cancer (mCRPC) in a managed care population in the United States. American Society of Clinical Oncology, 2020.

2. De Bono JS, Logothetis CJ, Molina A, et al. Abiraterone and increased survival in metastatic prostate cancer. New England Journal of Medicine. 2011;364:1995-2005.

3. Scher HI, Fizazi K, Saad F, et al. Increased survival with enzalutamide in prostate cancer after chemotherapy. New England Journal of Medicine. 2012;367:1187-1197.

4. Tannock IF, De Wit R, Berry WR, et al. Docetaxel plus prednisone or mitoxantrone plus prednisone for advanced prostate cancer. New England Journal of Medicine. 2004;351:1502-1512.

5. De Bono JS, Oudard S, Ozguroglu M, et al. Prednisone plus cabazitaxel or mitoxantrone for metastatic castration-resistant prostate cancer progressing after docetaxel treatment: a randomised open-label trial. The Lancet. 2010;376:1147-1154.

6. Kantoff PW, Higano CS, Shore ND, et al. Sipuleucel-T immunotherapy for castrationresistant prostate cancer. New England Journal of Medicine. 2010;363:411-422.

7. Parker C, Nilsson S, Heinrich D, et al. Alpha emitter radium-223 and survival in metastatic prostate cancer. New England Journal of Medicine. 2013;369:213-223.

8. Parker CC, Coleman RE, Sartor O, et al. Three-year safety of radium-223 dichloride in patients with castration-resistant prostate cancer and symptomatic bone metastases from phase 3 randomized alpharadin in symptomatic prostate cancer trial. European urology. 2018;73:427-435.

9. Frantellizzi V, Farcomeni A, Follacchio GA, et al. A 3-variable prognostic score (3-PS) for overall survival prediction in metastatic castration-resistant prostate cancer treated with 223 Radium-dichloride. Annals of nuclear medicine. 2018;32:142-148.

10. Sartor O, Coleman R, Nilsson S, et al. An exploratory analysis of alkaline phosphatase, lactate dehydrogenase, and prostate-specific antigen dynamics in the phase 3 ALSYMPCA trial with radium-223. Annals of Oncology. 2017;28:1090-1097.

11. Wong WW, Anderson EM, Mohammadi H, et al. Factors associated with survival following radium-223 treatment for metastatic castration-resistant prostate cancer. Clinical genitourinary cancer. 2017;15:e969-e975.

12. Yamamoto Y, Okuda Y, Kanaki T, et al. Clinical indicators for predicting prognosis after radium-223 administration in castration-resistant prostate cancer with bone metastases. International Journal of Clinical Oncology. 2021;26:192-198.

13. Parikh S, Murray L, Kenning L, et al. Real-world outcomes and factors predicting survival and completion of radium 223 in metastatic castrate-resistant prostate cancer. Clinical Oncology. 2018;30:548-555.

14. Frantellizzi V, Monari F, Mascia M, et al. Validation of the 3-variable prognostic score (3-PS) in mCRPC patients treated with 223 Radium-dichloride: a national multicenter study. Annals of Nuclear Medicine. 2020;34:772-780.

15. Sartor O, Coleman R, Nilsson S, et al. Effect of radium-223 dichloride on symptomatic skeletal events in patients with castration-resistant prostate cancer and bone metastases: 
results from a phase 3, double-blind, randomised trial. The Lancet Oncology. 2014;15:738-746.

16. 16. comparison of the analgesic effect and toxicity of $153 \mathrm{Sm}$ radioisotope treatment in monotherapy and combined therapy including local external beam radiotherapy (EBRT) among metastatic castrate resistance prostate cancer (mCRPC) patients with painful bone metastases. Neoplasma. 2013;60:328-333.

17. INESSS. EXTRACT NOTICE TO THE MINISTER - XOFIGO. 2015.

18. Etchebehere EC, Milton DR, Araujo JC, et al. Factors affecting 223 Ra therapy: clinical experience after 532 cycles from a single institution. European journal of nuclear medicine and molecular imaging. 2016;43:8-20.

19. Saad F, Gillessen S, Heinrich D, et al. Disease characteristics and completion of treatment in patients with metastatic castration-resistant prostate cancer treated with radium-223 in an international early access program. Clinical genitourinary cancer. 2019;17:348-355. e345.

20. Saad F, Keizman D, O'Sullivan JM, et al. Analysis of overall survival by number of radium-223 injections received in an international expanded access program (iEAP). American Society of Clinical Oncology, 2016.

21. Heidenreich A, Gillessen S, Heinrich D, et al. Radium-223 in asymptomatic patients with castration-resistant prostate cancer and bone metastases treated in an international early access program. BMC cancer. 2019;19:1-10.

22. Saad F, Carles J, Gillessen S, et al. Radium-223 international early access program investigators. Radium-223 and concomitant therapies in patients with metastatic castration-resistant prostate cancer: an international, early access, open-label, single-arm phase 3b trial. Lancet Oncol. 2016;17:1306-1316.

23. George DJ, Sartor O, Miller K, et al. Treatment patterns and outcomes in patients with metastatic castration-resistant prostate cancer in a real-world clinical practice setting in the United States. Clinical genitourinary cancer. 2020;18:284-294. 


\section{Figures and Tables}

Fig. 1. Kaplan-Meier estimate of overall survival between risk groups.

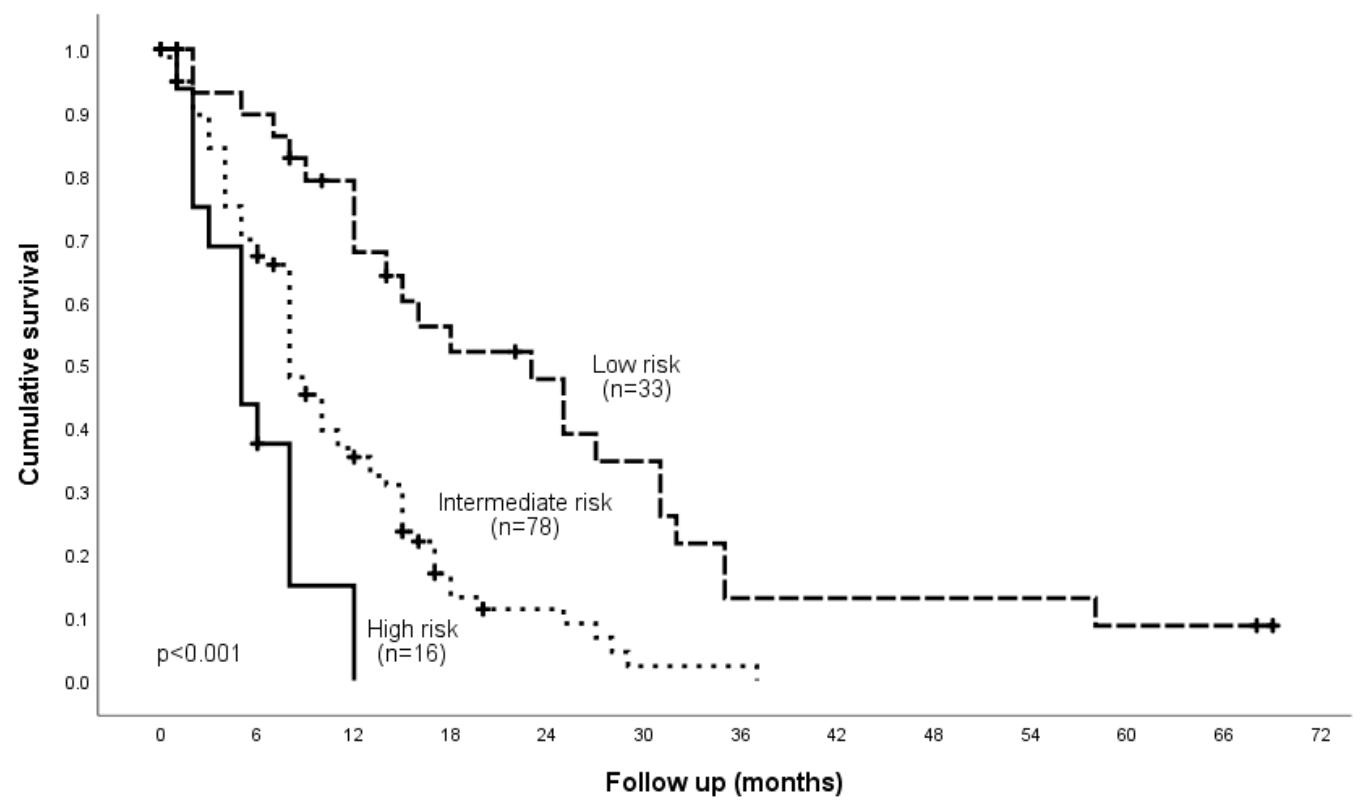

\begin{tabular}{|l|l|l|l|l|}
\hline \multicolumn{2}{|l|}{ Table 1. Characteristics of patients treated with ${ }^{\mathbf{2 2}} \mathbf{R a}$} \\
\hline Parameter & Median & Range & $\begin{array}{l}\text { Interquartile } \\
\text { range }\end{array}$ & Number of patients \\
\hline Age (years) & 72 & $48-89$ & $64-80$ & $\mathrm{~N}=133$ \\
\hline Baseline ECOG PS & & & & \\
0 & & & & $35(26 \%)$ \\
1 & & & $74(56 \%)$ \\
2 & & & $23(17 \%)$ \\
Missing & & & & $1(1 \%)$ \\
\hline Prior systemic therapies & & & \\
Docetaxel & & & $84(63 \%)$ \\
Abiraterone & & & $75(58 \%)$ \\
Cabazitaxel & & & $11(8 \%)$ \\
Enzalutamide & & & $50(38 \%)$ \\
Other & & & $19(14 \%)$ \\
\hline
\end{tabular}




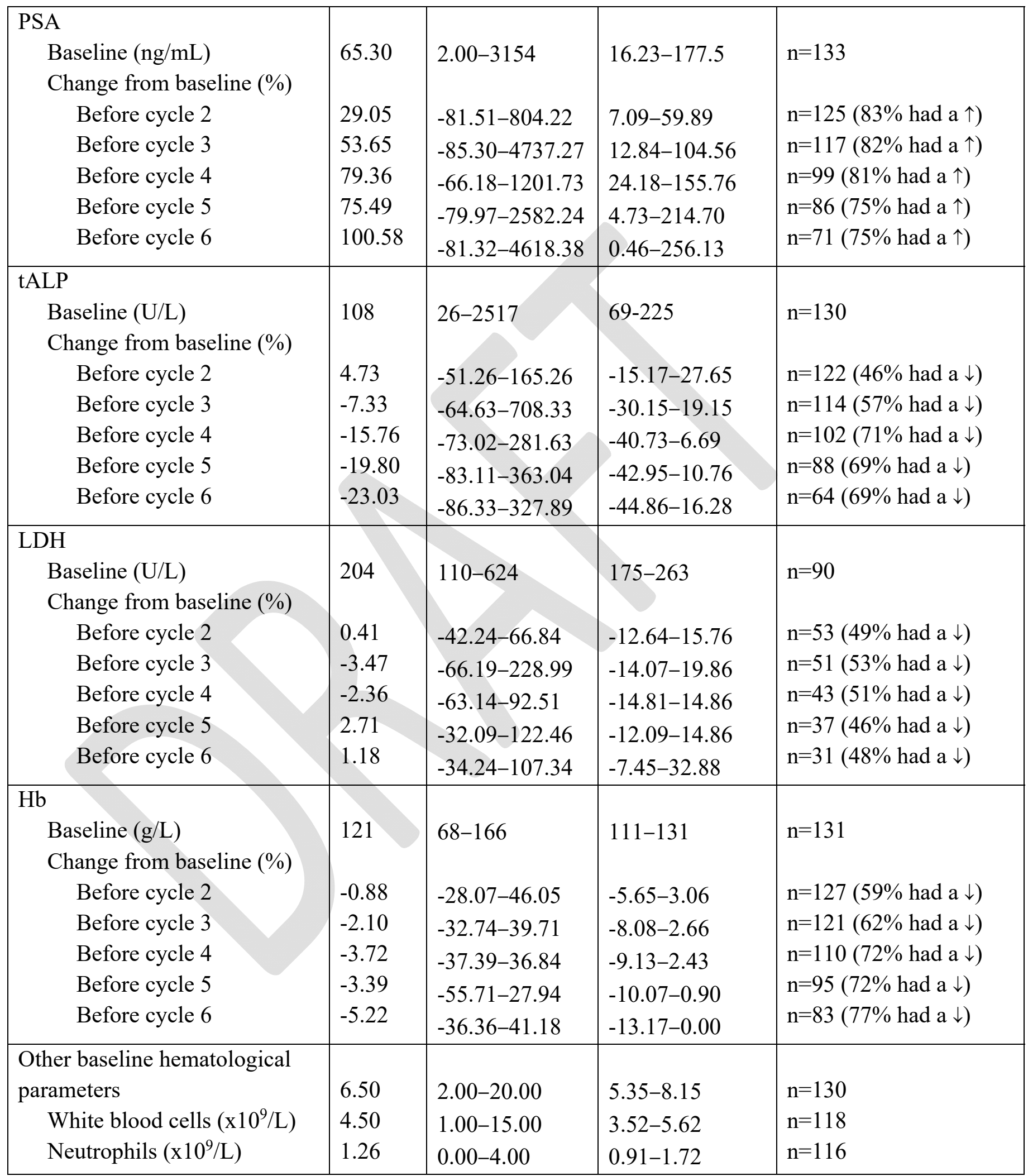




\begin{tabular}{|l|l|l|l|l|}
\hline $\begin{array}{l}\text { Lymphocytes }\left(\mathrm{x} 10^{9} / \mathrm{L}\right) \\
\text { Platelets }\left(\mathrm{x} 10^{9} / \mathrm{L}\right) \\
\text { NLR }\end{array}$ & $\begin{array}{l}228 \\
\text { Number of }{ }^{223} \mathrm{Ra} \text { cycles } \\
\text { completed }\end{array}$ & $\begin{array}{l}97-654 \\
0.61-87.60\end{array}$ & $\begin{array}{l}187-287 \\
2.48-4.86\end{array}$ & $\begin{array}{l}\mathrm{n}=131 \\
\mathrm{n}=116\end{array}$ \\
2 & & & & \\
3 & & & $7(5 \%)$ \\
4 & & & $17(13 \%)$ \\
5 & & & $8(6 \%)$ \\
6 & & & $9(7 \%)$ \\
7 & & & $72(54 \%)$ \\
12 & & & $2(2 \%)$ \\
\hline $\begin{array}{l}\text { EBRT } \\
\text { Before }{ }^{223} \mathrm{Ra}\end{array}$ & & & $3(2 \%)$ \\
During ${ }^{223} \mathrm{Ra}$ & & & \\
Before and/or during ${ }^{223} \mathrm{Ra}$ & & & $61(46 \%)$ \\
\hline
\end{tabular}

$\uparrow$ : increase ; $\downarrow$ : decrease. ${ }^{\dagger}$ Other therapies included Custirsen $(n=8)$, PROSTVAC $(n=6)$, Ipilimumab ( $\mathrm{n}=3$ ), and tazatinib ( $\mathrm{n}=2$ ). ECOG PS: Eastern Cooperative Oncology Group performance status; EBRT: external beam radiation treatment; Hb: hemoglobin; LDH: lactate dehydrogenase; NLR: neutrophil-to-lymphocyte ratio; PSA: prostate-specific antigen; tALP: total alkaline phosphatase.

\begin{tabular}{|l|l|}
\hline \multicolumn{2}{|l|}{ Table 2. Reasons for early cessation of Ra-223 treatment (n=50) } \\
\hline Reason & Number of patients \\
\hline Death & $10(20 \%)$ \\
\hline Patient's decision & $7(14 \%)$ \\
\hline Clinical deterioration (ECOG PS 3-4) & $6(12 \%)$ \\
\hline Disease progression & $5(10 \%)$ \\
\hline Visceral disease & $4(8 \%)$ \\
\hline Myelotoxicity of treatment & $6(12 \%)$ \\
\hline Non-hematologic toxicity of treatment & $1(2 \%)$ \\
\hline Sepsis & $3(6 \%)$ \\
\hline Medullary cord compression & $3(6 \%)$ \\
\hline $\begin{array}{l}\text { Pathological spinal fracture without } \\
\text { surgical fixation }\end{array}$ & $1(2 \%)$ \\
\hline Unknown & $4(8 \%)$ \\
\hline
\end{tabular}

ECOG PS: Eastern Cooperative Oncology Group performance status. 


\begin{tabular}{|l|l|l|l|}
\hline \multicolumn{3}{|l|}{ Table 3. Univariate analysis of possible predictive parameters for overall } \\
survival using log-rank test (Kaplan-Meier method)
\end{tabular}




\begin{tabular}{|c|c|c|c|}
\hline $\begin{array}{l}\text { Baseline tALP (U/L) } \\
\quad<110(\mathrm{n}=66) \\
\quad>110(\mathrm{n}=64)\end{array}$ & $\begin{array}{l}12.0 \\
8.0\end{array}$ & $\begin{array}{l}8.9-15.1 \\
7.4-8.6\end{array}$ & 0.001 \\
\hline $\begin{array}{l}\text { tALP decline } \\
\text { Yes }(n=72) \\
\text { No }(n=30)\end{array}$ & $\begin{array}{l}12.0 \\
9.0\end{array}$ & $\begin{array}{l}9.9-14.1 \\
6.4-11.6\end{array}$ & 0.60 \\
\hline $\begin{array}{l}\text { Baseline } \mathrm{Hb}(\mathrm{g} / \mathrm{L}) \\
\quad<120(\mathrm{n}=61) \\
\geq 120(\mathrm{n}=70)\end{array}$ & $\begin{array}{l}8.0 \\
13.0\end{array}$ & $\begin{array}{l}6.9-9.1 \\
10.4-15.6\end{array}$ & $<0.001$ \\
\hline $\begin{array}{r}\text { Baseline NLR } \\
\quad<3.5(\mathrm{n}=55) \\
\geq 3.5(\mathrm{n}=61)\end{array}$ & $\begin{array}{l}10.0 \\
10.0\end{array}$ & $\begin{array}{l}7.6-12.4 \\
5.5-14.8\end{array}$ & 0.90 \\
\hline $\begin{array}{l}\text { Baseline LDH }(\mathrm{U} / \mathrm{L}) \\
\quad<205(\mathrm{n}=45) \\
\geq 205(\mathrm{n}=45)\end{array}$ & $\begin{array}{l}15.0 \\
8.0\end{array}$ & $\begin{array}{l}10.9-19.1 \\
5.0-11.0\end{array}$ & 0.065 \\
\hline $\begin{array}{l}\text { EBRT } \\
\text { During Ra-223 }(\mathrm{n}=20) \\
\text { Not during Ra-223 }(\mathrm{n}=113)\end{array}$ & $\begin{array}{l}10.0 \\
9.0\end{array}$ & $\begin{array}{l}3.5-16.5 \\
7.1-10.9\end{array}$ & 0.57 \\
\hline $\begin{array}{l}\text { Before }(\mathrm{n}=61) \\
\text { Not before }(\mathrm{n}=72)\end{array}$ & $\begin{array}{l}9.0 \\
11.0\end{array}$ & $\begin{array}{l}7.5-10.6 \\
4.5-17.5\end{array}$ & 0.072 \\
\hline $\begin{array}{l}\begin{array}{l}\text { During and/or before Ra-223 } \\
(\mathrm{n}=70)\end{array} \\
\text { Not during nor before Ra-223 } \\
(\mathrm{n}=63)\end{array}$ & $\begin{array}{l}9.0 \\
11.0\end{array}$ & $\begin{array}{l}7.3-10.7 \\
5.0-17.0\end{array}$ & 0.051 \\
\hline
\end{tabular}

CI: confidence interval; EBRT: external beam radiation treatment; ECOG PS: Eastern Cooperative Oncology Group performance status; Hb: hemoglobin; LDH: lactate dehydrogenase; NLR: neutrophil-to-lymphocyte ratio; OS: overall survival; PSA: prostatespecific antigen; tALP: total alkaline phosphatase. 


\begin{tabular}{|l|l|l|l|}
\hline \multicolumn{3}{|l|}{ Table 4. Multivariate analysis of baseline parameters predicting overall survival } \\
\hline Covariates & $\begin{array}{l}\text { Hazard ratio for } \\
\text { death }\end{array}$ & $\mathbf{9 5 \%}$ CI & $\mathbf{p}$ \\
\hline $\begin{array}{c}\text { Baseline ECOG PS } \\
2 \text { vs. } 0-1\end{array}$ & 1.94 & $1.30-2.90$ & $\mathbf{0 . 0 0 1}$ \\
\hline $\begin{array}{c}\text { Baseline Hb } \\
\geq 120 \text { vs. }<120 \mathrm{~g} / \mathrm{L}\end{array}$ & 0.50 & $0.29-0.85$ & $\mathbf{0 . 0 1 1}$ \\
\hline $\begin{array}{c}\text { Baseline LDH } \\
>205 \text { vs. } \leq 205 \mathrm{U} / \mathrm{L}\end{array}$ & 1.50 & $0.89-2.53$ & 0.13 \\
\hline $\begin{array}{c}\text { Baseline tALP } \\
>110 \text { vs. } \leq 110 \mathrm{U} / \mathrm{L}\end{array}$ & 1.58 & $0.92-2.74$ & 0.10 \\
\hline $\begin{array}{l}\text { Previous use of } \\
\text { docetaxel } \\
\text { Yes vs. No }\end{array}$ & 1.86 & $1.08-3.22$ & $\mathbf{0 . 0 2 6}$ \\
\hline $\begin{array}{l}\text { Previous use of } \\
\text { abiraterone } \\
\text { Yes vs. No }\end{array}$ & 1.15 & $0.65-2.06$ & 0.063 \\
\hline $\begin{array}{c}\text { EBRT before } \\
\text { Yes vs. No }\end{array}$ & 1.09 & $0.64-1.87$ & 0.75 \\
\hline
\end{tabular}

CI: confidence interval; EBRT: external beam radiation treatment; ECOG PS: Eastern Cooperative Oncology Group performance status; $\mathrm{Hb}$ : hemoglobin; LDH: lactate dehydrogenase; tALP: total alkaline phosphatase.

\begin{tabular}{|c|c|c|c|c|c|c|}
\hline Risk group & $\begin{array}{l}\text { Total } \\
\text { score }\end{array}$ & $\begin{array}{l}\text { Number } \\
\text { at risk }\end{array}$ & $\begin{array}{l}\text { Number of } \\
\text { events }\end{array}$ & $\begin{array}{l}\begin{array}{l}\text { Median OS } \\
\text { (months) }\end{array} \\
\end{array}$ & $\begin{array}{l}95 \% \text { CI } \\
\text { (months) }\end{array}$ & $\mathbf{p}$ \\
\hline Low & 2 & 33 & 23 & 23.0 & $12.8-33.2$ & \multirow[t]{2}{*}{$<0.001$} \\
\hline Intermediate & $3-4$ & 78 & 68 & 8.0 & $6.7-9.3$ & \\
\hline High & $5-6$ & 16 & 15 & 5.0 & $3.1-6.9$ & \\
\hline
\end{tabular}

Baseline ECOG PS: $0-1=0$ point; $2=2$ points. Baseline tALP: $\leq 110 \mathrm{U} / \mathrm{L}=1$ point; $>110 \mathrm{U} / \mathrm{L}=2$ points. Baseline $\mathrm{Hb}: \geq 120 \mathrm{~g} / \mathrm{L}=1$ point; $<120 \mathrm{~g} / \mathrm{L}=2$ points. CI: confidence interval; ECOG PS: Eastern Cooperative Oncology Group performance status; Hb: hemoglobin; OS: overall survival; tALP: total alkaline phosphatase. 